\title{
Physical Activity for Families ${ }^{1}$
}

\section{Jamie C. Stolarz, Karla P. Shelnutt, Andrea Nikolai, and Annie Sheldon Wallau²}

Remember playing games such as hopscotch, freeze tag, and kickball during recess? It felt great to go outside, get your blood flowing, and work your muscles. Being active does not have to be a thing of the past. What better way to start than with the activities you love the most? It's time to grab your family and start moving!

This publication highlights health benefits and recommendations for physical activity. It also includes tips for being active and suggests fun activities that the whole family can do together. If you have any existing health conditions, consult your physician before beginning a physical activity program.

\section{Health Benefits of Physical Activity}

Being physically active has many health benefits. Health benefits start immediately after exercising. Even short episodes of physical activity are beneficial, and research shows that individuals of all ages benefit from physical activity (Department of Health and Human Services, 2018b). Physical activity is good for mental and physical health.

\section{Mental Health}

Physical activity can reduce the risk of anxiety and depression and can help people sleep better. It can also keep your learning, thinking, and judgment skills sharp as you age and reduce the risk of dementia (including Alzheimer's disease) (Department of Health and Human Services, 2018b).

\section{Physical Health}

Physical activity can reduce the risk for many conditions and improve overall health. Health benefits associated with regular physical activity include the following (Department of Health and Human Services, 2018b):

- Increase the chances of living longer

- Help control weight

- Reduce the risk for cardiovascular disease and high blood pressure

- Reduce the risk for type 2 diabetes and metabolic syndrome

- Reduce the risk for certain cancers (colon, bladder, breast, endometrium, esophagus, kidney, lung, and stomach)

- Strengthen bones and muscles

- Improve the ability to do daily activities

- Prevent falls (for older adults) and injuries from falls

\section{Bone Health}

Although all the health benefits of physical activity are noteworthy, bone and muscle health are especially important. Healthy bones, joints, and muscles support the body and ensure that a person can perform daily activities and be physically active. Research has shown

1. This document is FCS8922, one of a series of the Department of Family, Youth and Community Sciences, UF/IFAS Extension. Original publication date July 2013. Revised February 2022. Visit the EDIS website at https://edis.ifas.ufl.edu for the currently supported version of this publication.

2. Jamie C. Stolarz, M.S., RD, LDN, Lakeland, FL; Karla P. Shelnutt, associate professor, Extension nutrition specialist, Department of Family, Youth and Community Sciences, and UF/IFAS Extension nutrition program leader; Andrea Nikolai, Extension agent II, M.P.H., UF/IFAS Extension Polk County; and Annie Sheldon Wallau, county Extension director, Extension agent II, M.N.M., UF/IFAS Extension Clay County; UF/IFAS Extension, Gainesville, FL 32611.

The Institute of Food and Agricultural Sciences (IFAS) is an Equal Opportunity Institution authorized to provide research, educational information and other services

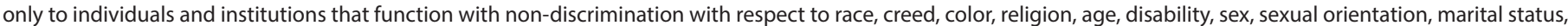

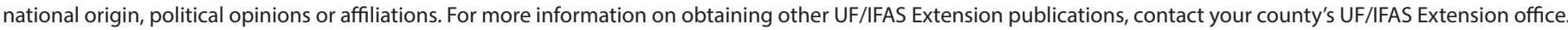
U.S. Department of Agriculture, UF/IFAS Extension Service, University of Florida, IFAS, Florida A \& M University Cooperative Extension Program, and Boards of County Commissioners Cooperating. Andra Johnson, dean for UF/IFAS Extension. 
that moderate-intensity physical activities that strengthen the bones and muscles can slow the loss of bone density that comes with age (Department of Health and Human Services, 2018b). Weight-bearing activities are especially important for children and teens, because the best time to build healthy bones is during years of rapid growth (American Academy of Orthopedic Surgeons, 2020).

To build and maintain healthy bones, it is important to participate in weight-bearing exercises. Doing so can reduce the risk for developing osteoporosis, a condition in which the bones become brittle and are more likely to break. Examples of weight-bearing activities include the following (American Academy of Orthopedic Surgeons, 2020):

- Brisk walking, jogging, and hiking

- Yard work (pushing a lawn mower, heavy gardening)

- Jumping rope and playing hopscotch

- Basketball, volleyball, and soccer

- Dancing

- Stair climbing

- Tennis and badminton

- Bowling

- Weight training with free weights or machines

\section{Physical Activity}

Physical activity is any muscle movement that requires energy beyond your resting level (Department of Health and Human Services, 2018b). In other words, physical activity increases your heart rate.

Physical activities can be categorized by their intensity level, or how hard the body has to work. Activities that require a moderate to vigorous level of intensity are the types of activities that get your heart pumping. The "talk test" is an easy way to measure the intensity of an activity. During a moderate-intensity physical activity, it is easy to talk but almost impossible to sing. Vigorous physical activities are more intense than moderate-intensity physical activities and use more energy. During vigorous-intensity activities, it is difficult to say more than a few words without taking a breath. Fortunately, moderate-intensity physical activities are generally safe for most people. Examples of moderate and vigorous physical activities are listed in Table 1 (CDC, 2020).
Table 1. Moderate and vigorous physical activities.

\begin{tabular}{|l|l|}
\hline Moderate & Walking briskly (not race-walking) \\
& Water aerobics \\
& Bicycling (slower than $10 \mathrm{mph}$ ) \\
& Tennis (doubles) \\
& Ballroom dancing \\
& General gardening \\
\hline Vigorous & Race-walking \\
& Jogging \\
& Running \\
& Swimming laps \\
& Tennis (singles) \\
& Aerobic dancing \\
Bicycling (faster than 10 mph) \\
Jumping rope \\
Heavy gardening \\
Hiking uphill or with a heavy backpack
\end{tabular}

\section{Recommendations}

To gain the most health benefits from physical activity, you should do the right amount and types of activities for your age. The recommended guidelines for children, adults, and older adults are listed below.

\section{Children}

In general, children are more active than adults, so they may already meet their physical activity needs. Preschoolaged children should be physically active throughout the day through active play. Children and adolescents ages 6 through 17 years old should do 60 minutes or more of moderate to vigorous physical activity every day (Department of Health and Human Services, 2018b). It is especially important for children to participate in aerobic activities, as well as muscle- and bone-strengthening activities.

\section{AEROBIC}

Aerobic activities also can be called "cardio." They quicken breathing and get the heart beating faster. Aerobic activities should make up most of a child's 60 (or more) minutes of daily physical activity. These can include moderate-intensity or vigorous-intensity activities, but be sure to include vigorous-intensity aerobic activities at least 3 days per week (Department of Health and Human Services, 2018b).

\section{MUSCLE-STRENGTHENING}

Children can strengthen their muscles doing a wide variety of age-appropriate activities. Gymnastics, playing on a jungle gym, push-ups, and climbing trees are musclestrengthening activities. Include them at least 3 days per week (Department of Health and Human Services, 2018b). 


\section{BONE-STRENGTHENING}

As previously mentioned, building and maintaining strong bones at this stage is critical for health later in life. Running and jumping rope are examples of bone-strengthening activities that many children already enjoy. Include them at least 3 days per week (Department of Health and Human Services, 2018b).

\section{Adults}

Adults should focus on two types of physical activity: aerobic activities and muscle-strengthening activities.

\section{AEROBIC}

Adults can meet their aerobic needs in a variety of ways (Department of Health and Human Services, 2018b). Adults can participate in 150 minutes ( 2 hours and 30 minutes) of moderate-intensity aerobic activity every week, 75 minutes (1 hour and 15 minutes) of vigorous-intensity aerobic activity every week, or an equivalent mix of moderate- and vigorous-intensity aerobic activity.

Adults do not have to participate in their weekly physical activity all at once. Research shows that any amount of moderate to vigorous physical activity counts towards the target range of activity. Bouts of any duration can be beneficial (Department of Health and Human Services, 2018a).

\section{MUSCLE-STRENGTHENING}

Adults should do muscle-strengthening activities 2 or more days of the week. These activities should work all the major muscle groups including legs, hips, back, abdomen, chest, shoulders, and arms.

Some activity is better than no activity. Adults should sit less and move more throughout the day. Adults who sit less and do any amount of moderate- to vigorous-intensity physical activity gain some health benefits (Department of Health and Human Services, 2018b).

\section{Older Adults}

Physical activity is one of the most important things that older adults can do to maintain their health. It can prevent a number of health problems so an older adult can remain independent in doing daily activities. Adults who are 65 years or older and generally fit with no serious health conditions can follow the same physical activity recommendations for adults listed above (Department of Health and Human Services, 2018b).

\section{Adults with Chronic Health Conditions and Adults with Disabilities}

Adults who are able should also follow the same recommendations for aerobic and muscle-strengthening activities listed above. Adults who cannot meet the above guidelines should do what they can according to their ability and avoid inactivity. Adults with chronic conditions or disabilities should also be under the care of a health care provider and consult with them about appropriate amounts and types of activity (Department of Health and Human Services, 2018b).

\section{Children and Families}

Participating in family physical activities can have many benefits, including better communication between parents and children, more quality time spent together, improved physical health and fitness, increased mental health, and weight management. Also, helping children learn to enjoy being physically active can help them stay active in the future.

It is important to be a good role model and to encourage physical activity during childhood because inactive children are much more likely to be inactive adults. Studies have shown that children who feel support from friends and families to be active or are surrounded by others interested in physical activity are more likely to be active (Let's Move, n.d.).

\section{Get started!}

Physical activity does not have to be expensive or boring. Many activities are free or inexpensive. For example, jumping rope, hiking, and playing tag are free activities the family can do together. Physical activity should be fun. Switch up the routine and try something new. Explore a new bike route or try a new sport. The possibilities are endless!

Some suggestions for family activities are listed below. Many more are out there, so don't be afraid to get creative!

- Plant a garden

- Walk, jog, run

- Hike

- Swim

- Do yoga or Pilates

- Walk the dog

- Jump rope 
- Play tag

- Dance or do Zumba

- Bowl

- Ice-skate, roller-skate, rollerblade

- Play racquetball

- Row: kayak, canoe, paddleboat

- Play freeze tag

- Stretch

- Play catch

- Play hide-and-seek

- Bike ride

- Play a sport (baseball, basketball, football, softball, soccer, tennis)

\section{For More Information}

UF/IFAS Extension Family and Consumer Sciences (FCS) educator: https://sfyl.ifas.ufl.edu/find-your-local-office/

WIC nutritionist at your county Health Department: https://www.signupwic.com/

Finding a nutrition expert or a qualified registered dietitian nutritionist in your area: https://www.eatright.org/ find-a-nutrition-expert

\section{Recommended Websites}

MyPlate: http://www.choosemyplate.gov/

Centers for Disease Control and Prevention: https://www. cdc.gov/physicalactivity/index.html

Healthy People 2030: https://health.gov/healthypeople?_ga $=2.213578333 .893378459 .1628777667$ 319019754.1628777667

Physical Activity for Children: https://www.cdc.gov/ physicalactivity/basics/children/index.htm

Move Your Way-Help your kids get more physical activity: https://health.gov/moveyourway/get-kids-active

\section{References}

American Academy of Orthopedic Surgeons. (2020). Weightbearing Exercise for Women and Exercise and Bone Health. Retrieved from https://orthoinfo.aaos.org/en/ staying-healthy/exercise-and-bone-health/
CDC. (2020). How much physical activity do adults need? Retrieved from https://www.cdc.gov/physicalactivity/basics/adults/index.htm\#: :text=Moderate\%2Dintensity\%20 aerobic\%20physical\%20activity,words\%20to\%20your\%20 favorite $\% 20$ song

CDC. (2021). Physical Activity: Physical Activity and Health. Retrieved from http://www.cdc.gov/physicalactivity/everyone/health/index.html

Department of Health and Human Services. (2018a). Physical Activity Guidelines Advisory Committee Scientific Report. Part A. Executive Summary. Retrieved from https://health.gov/sites/default/files/2019-09/02_A_Executive_Summary.pdf

Department of Health and Human Services. (2018b). Physical Activity Guidelines for Americans, $2^{\text {nd }}$ Edition. Retrieved from https://health.gov/sites/default/files/2019-09/Physical_Activity_Guidelines_2nd_edition.pdf

Let's Move. (n.d.). Active Families. Retrieved from http:// www.letsmove.gov/active-families 